\title{
Trust in Virtual Teams: Towards an Integrative Model of Trust Formation
}

\author{
Yu-Ting Caisy Hung \\ Kelley School of Business \\ Indiana University \\ Bloomington IN 47405 \\ yhung@indiana.edu
}

\author{
Alan R. Dennis \\ Kelley School of Business \\ Indiana University \\ Bloomington IN 47405 \\ ardennis@indiana.edu
}

\author{
Lionel Robert \\ Kelley School of Business \\ Indiana University \\ Bloomington IN 47405 \\ lrobert@indiana.edu
}

\begin{abstract}
Traditional models of trust have seen trust as being created as a result of a long history of interaction, but recent studies of trust in virtual teams have shown the existence of high initial trust among team members. This paper proposes an integrated model of trust that encompasses both the traditional view of trust and the swift trust found in virtual teams. Based on the dual process theories of cognition, we argue that individuals form trust attitudes via three distinct routes at different stages of a relationship: the peripheral route, the central route, and the habitual route, irrespective. In the initial stages of a relationship when individuals lack information about each other, they rely on peripheral cues (e.g., third party information, social categories, roles, and rules) to form trust. Once individuals have shared history and knowledge of the other party, they use the central route, which involves the assessment of the other party's ability, integrity, and benevolence. Finally, after long periods of shared history in which the individuals develop a habitual pattern of trust, along with possible emotional bonds, they are no longer motivated to deliberately assess trust, and instead simply enact prior trust attitudes via the habitual route. The mediated communication environment predominantly used by virtual teams slows down the progression among the three routes, and increases perceived risk.
\end{abstract}

\section{Introduction}

New information and communication technologies (ICT) such as e-mail, groupware, and instant messaging are being adopted in the work place, and can enable new forms of organization such as virtual teams. A virtual team staffed by members across spatial, temporal, and/or organizational boundaries can be assembled on an asneeded basis for the duration of a project [15]. In virtual teams, members use ICT to facilitate communication and collaboration across distance, time, and/or organizational boundaries [15]. In many cases, members rarely see each other in person [24]. Virtual teams save time and travel expenses, provide easier access to experts and expand labor markets [8], but also present new challenges.

One such challenge is trust: The lack of physical interaction and the synergies that often accompany faceto-face communication may inhibit traditional ways of building trust [8]. Trust affects performance [25] and is critical in organizational cooperation, coordination, and control [35]. In computer mediated communication environments, which traditional social control based on authority gives away to self-direction and self-control, trust is even more critical [20].

Traditionally, trust has been seen as a result of history-dependent interaction where trust is based on both rationally and socially derived costs and benefits [27]. Trust is assumed to develop gradually over time based on direct personal interaction and communication [31, 35]. However, the use of computer mediated communication imposes limitations on direct personal interaction and communication. Members of a virtual team often have little prior history of working together and may never have met face-to-face. This, combined with the relatively short collaboration time, would lead traditional models of trust to predict that members of virtual teams should show low trust for one another. However, studies of trust in temporary teams [38] and in virtual teams [24, 25] have shown the existence of high initial trust among team members. Trust is observed to be high at the outset, even before the parties have any chance to interact [e.g., 26].

We believe that these seemingly contradictory views (developmental trust in traditional environments and swift trust in computer mediated communication environments) call for a reexamination of trust. In short, can we as IS researchers simply adopt the traditional models of trust or do we need to develop new models better suited to new ICTs? We believe that new models are needed. The main objective of this study is, therefore, to propose an integrated model that can address trust formation and 
maintenance in both traditional organizational settings and temporary virtual teams. Based on the dual process theories of cognition (such as the Elaboration Likelihood Model [7, 42] and the Heuristic-Systematic Model [9], we propose that trust is formed through different routes at different stages. The route an individual uses to form trust depends on his or her motivation and ability to process relevant information about other team members.

\section{Theories of Trust}

\subsection{The traditional developmental view of trust}

Trust is a psychological state that can be viewed from a rational or a social perspective. The rational perspective centers on the calculus of self-interest [e.g., 30], while the social perspective centers on moral duty or commitment. Although these two perspectives of trust seem to project fundamentally different images of trust, scholars have tried to reconcile these two diverse views. Kramer [27] argues that the conceptualization of trust should be contextual in that it acknowledges the role of both calculated self-interest and social consideration in trust judgments and choices. Trust should incorporate the calculative processes as part of the fundamental "arithmetic" of trust yet also include social and situational factors that influence the salience and relative weight afforded to various instrumental and non-instrumental concerns in such calculations. Hardin [21] argues that trust should be conceptualized as a three-part relation involving properties of the trustor, attributes of a trustee, and a specific context over which trust is conferred.

Mayer, et al.'s [35] model of trust, incorporating the properties of the trustor, the attributes of the trustee, and the risk associated with the situation, is one of the more broadly adopted traditional models of trust [e.g., 2, 14]. In this model, trust in a dyadic work relationship is defined as an individual's willingness to be vulnerable to the actions of the other involved party based on a particular action important to the trustor, irrespective of the trustor's ability to monitor or control the trustee. The extent to which a person is willing to trust another person is affected by the trustor's propensity to trust and the trustor's perceptions of the trustee's trustworthiness, determined by the trustee's ability, integrity, and benevolence perceived by the trustor. Based on one's belief of the involved parties' trustworthiness (i.e., the willingness to assume risk), his or her trust and subsequent trusting behavior (i.e., actually assume risk) is further determined by the assessment of risk in the situation. The distinction between trust and trust behavior lies in acknowledging the risks and actually assuming the risks. The perceptions of risk come from the trustor's assessment of gains or losses outside of the relationship with the particular trustee. In a given situation, the level of trust is compared to the level of perceived risk. Only if the level of trust surpasses the threshold of perceived risk, will the trustor engage in trusting behavior.

The traditional model views trust formation as a developmental process, which is closely intertwined with relationship development processes [32]. Trust is viewed as a result of history-dependent interaction [27] and is developed gradually through personal interaction [31, 35]. Theorized as a sequential iteration in which the achievement of trust at one level enables the development of trust at the next level [31], trust in a work relationship at different developmental stages (i.e., early, developing, and mature) takes on different characters and operates in different forms. The accumulated knowledge about others' capabilities, values, and behaviors through interaction allows an individual to base trust on cognitive assessment or affective response [32, 34, 48]. Cognitionbased trust results from deliberate assessment of others' characteristics and the process of weighing benefits of trusting over risks [31], whereas affect-based trust involves one's emotional bonds and sincere concern for the well-being of the others $[34,36]$. The evolution of trust is often considered a time-based process [31].

\subsection{Presumptive trust in virtual teams}

Paradoxically, high levels of trust have often been observed in initial relationships among members of temporary teams - teams that are formed around a common task with a finite life span. In a temporary team, members have never worked together before and do not expect to work together again and with limited time to work on a complex task, the team does not have ways to engage in more traditional, enduring forms of confidencebuilding activities that contribute to the development and maintenance of trust. Lacking the traditional sources of trust - familiarity, shared experience, reciprocal disclosure, threats and deterrents, fulfilled promises, and demonstrations of nonexploitation of vulnerability [38] people are expected to demonstrate low levels of trusting behaviors, yet studies have found the existence of high levels of trust during such interactions [e.g., 27].

Studies in global virtual teams (GVTs) also have observed high initial trust among team members [23, 24]. According to the traditional developmental view, limited trusting behaviors are expected in GVTs where members: have no common past or future, are culturally diverse and geographically dispersed, and communicate via various ICTs. The traditional developmental view of trust assumes that trust resides in personal relationships and past or future membership in common social networks that define the shared norms of obligation and responsibility [4]. The lack of past and future association among GVT members decreases the potential for trust [4, 
35]. Finally, the physical contact that contributes to trust formation [20] is often lacking in GVT. Nonetheless, high levels of trust have been observed in GVTs [23, 24].

Swift trust was first proposed to explain this paradoxical trusting behavior exhibited by members of temporary systems [38]. Rather than conceptualizing trust as cognitive or affective, trust is conferred "ex ante"; presumptively in situations where developed trusting relationships are absent [38]. Rapid development of trust in temporary systems is helped by role-based interaction (rather than person-based interaction), and by the greater use of category-driven information processing (rather than evidence-driven information processing) [38]. With insufficient time to build proper expectations from prior interactions, people in temporary systems tend to use expectations built on categories reflecting roles, cultural cues, or occupation- and identity-based stereotypes [5, 17, $37,38]$. These attribution processes contribute to the swift formation of trust by allowing individuals to act according to general principles associated with the role and/or the category rather than on specific individual personalities or personal relationships. In sum, individuals tend to presume trust and import it from other similar settings and presumptive trust is different from knowledge-based trust that is built upon personal relationships.

The traditional models of trust explain the evolution of trust that is mainly built upon accumulated personal knowledge, while the models of presumptive trust explain the high levels of trust observed in situations where personal- and history-based knowledge is not available. However, neither one provides a comprehensive and integrated view of trust. In addition, because they are derived from a more traditional communication environment, these models provide only partial answers to our question; it is still unclear to us how trust is formed and maintained in a technology-enabled communication and collaboration environment. Initial high trust is more likely to be robust when the parties have frequent face-toface interaction [37]. Lacking the opportunities for faceto-face interaction, how do virtual teams utilize ICTs to facilitate trust building and maintenance among their members? This paper addresses the question of how virtual team members form trust in computer mediated communication environments by reconciling and extending the two seemingly contradictory views of trust and by incorporating existing literature in computermediated communication into the framework.

\section{Toward an Integrated Model of Trust}

Traditional developmental models of trust argue that trust evolves from low to high as one's first-hand knowledge of the interacting parties slowly accumulates ${ }^{1}$. Yet, it is also possible that trust can be formed through processes at different stages of a trusting relationship [32, 34, 36, 48]. Rather than arguing that individuals form trust solely through one process, we propose that individuals form trust through three possible routes depending upon the stage of a trusting relationship.

In order to develop our model, we must first examine the underlying theoretical basis for our model: dual process theories of cognition. Two complementary dual process theories of cognition emerged independently in 1980 s to explain the way in which individuals form attitudes. The Elaboration Likelihood Model (ELM) [7, 42] postulates that there are two distinct routes to attitude formation (central and peripheral); under the central route, attitude formation results from an individual's deliberate, cognitively active, consideration of available information evaluating the true merits of a particular attitudinal position, while under the peripheral route, attitude forms as a result of a less cognitively involved assessment of simple positive or negative cues in the context (e.g., the attractiveness or reputation of the person providing information). The Heuristic-Systematic Model (HSM) [9] argues that attitudes are formed by the systematic application of considerable cognitive effort to comprehend and evaluate the available information, or by exerting little cognitive energy to use simple heuristics on readily accessible information (e.g., the source's identity). For simplicity, we will adopt the terminology of ELM.

The choice of which route to use depends upon an individual's 1) motivation and 2) ability to expend cognitive effort $[9,42]$. Using the central route requires more cognitive effort, and unless there is a clear value to do so, individuals tend to avoid it $[9,42]$. Thus an individual has to be motivated and involved in the situation before he or she is willing to expend the effort to use the central route. If the necessary information is not available to use the central route, even the most motivated and cognitively capable individual must use simple heuristics driven by peripheral cues [9, 42]. Attitudes formed through the cognitively intensive central route tend to be relatively enduring and predictive of subsequent behavior, while those formed through the peripheral route tend to be less stable [42].

\subsection{Model Overview}

The dual process theories of cognition provide a basis for integrating the traditional development view of trust and the models of presumptive trust. We propose that

\footnotetext{
${ }^{1}$ For simplicity of presentation, we will assume that the parties to the trusting relationship are indeed worthy of trust, unless otherwise stated. Obviously, if the parties are not trustworthy, then increasing knowledge of each other will spawn distrust, not trust.
} 
individuals have three possible routes by which to form trust (see Figure 1). When people first meet, the lack of personal knowledge about the interacting parties hinders their ability to engage in deliberate assessment, even when they have high motivation to do so. This forces people to use simple heuristics based on the peripheral cues embedded in the interaction environment. Therefore, information such as the parties' social categories and roles, and organizational norms become dominant in forming trust. This provides an explanation for why individuals in newly-formed teams or temporary virtual teams tend to rely on category-driven information processing to presume trust.

As individuals gradually accumulate personal knowledge of others, they now have the ability to cognitively engage in information deliberation. The ability, plus the motivation, to engage in deliberate assessment of the interacting parties induces the use of the central route of information processing. Trust at this stage is based on the active evaluation of the interacting parties' trustworthiness in terms of their ability, integrity, and benevolence. This explains why individuals in established teams develop trust based on accumulated personal knowledge of ability, integrity, and benevolence.

As individuals gain more knowledge about each other and build a history of positive and successful trust transactions, their motivation to deliberate on relevant information may be significantly reduced. Built upon extensive knowledge of the involved parties, individuals may form a habitual pattern of making trust judgments [46], and even begin to identify strongly with others' needs, preferences, and priorities, and come to see them as their own [32]. This identification-based trust often involves strong emotional bonds, and concerns for the others' well-being $[34,36]$. With the tendency to avoid expending cognitive effort $[9,42]$, this habitual pattern and/or personal identification reduces the motivation to assess relevant information and thus reduces the likelihood of using the central route. The stockpile of accumulated knowledge and the habitual pattern of trusting decisions prevent the return to the peripheral route and its reliance on peripheral cues; instead, individual simply enact their previous trusting decisions.

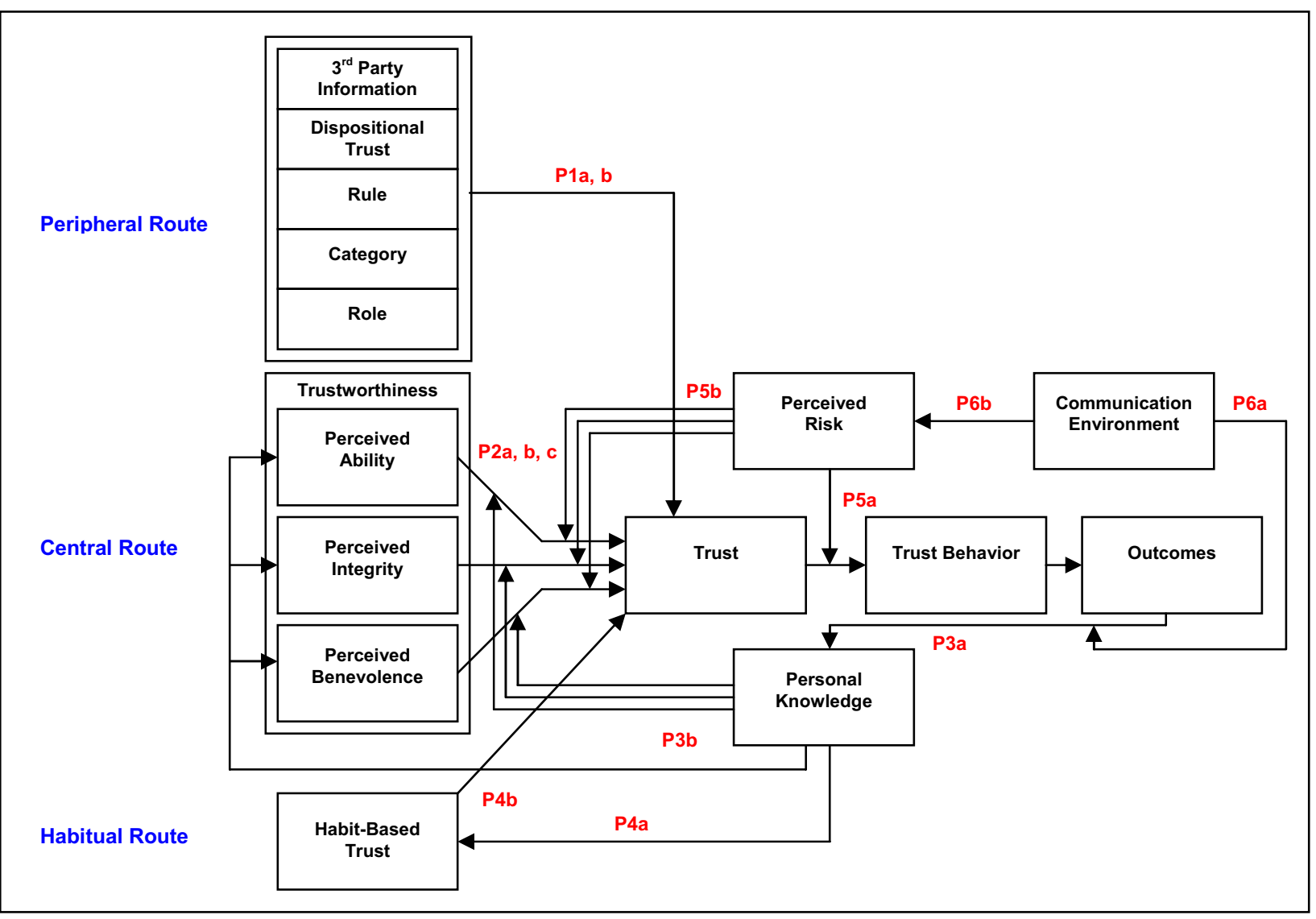

Figure 1. The Model 
While the proposed model is based on the dual process theories of cognition, which posit two routes of attitude formation, we feel the need to expand these theories and include a third route: the habitual route. According to Triandis [46] both intentional and automatic or subconscious factors are important determinants of human behavior. Intentional behavior is driven by human conscious cognitive effort, while automatic or subconscious behavior, such as habits, occurs without self-instruction [46]. As individuals accumulate personal knowledge of the interacting parties and their trusting decisions have become routine, they are more likely to act under the influence of automatic or unconscious behaviors. In addition, the possibility of having developed close personal relationships and emotional bonds through prior positive trusting transactions further provides an alternative base of trust to cognitive perceptions $[34,36,48]$. This habitual route to attitude formation thus does not involve conscious assessment of the other parties either based on available peripheral cues or on relevant personal information.

\subsection{Peripheral route: Presumptive trust}

Dual process theories argue that to follow the central route of attitude change, one requires both the motivation and the ability to cognitively deliberate on information [9, 42]. When an individual is able to deliberate but has low motivation to do so, he or she is more likely to conserve cognitive resources and rely on peripheral cues. When an individual is motivated but is not able to deliberate, he or she is more likely to fall back on peripheral cues.

The presumptive trust observed in temporary [38] and virtual teams [23, 24], and at initial encounters in organizations [37] can be attributed to the peripheral route of information processing. In these encounters where individuals do not have the ability to engage in a full assessment of the interacting parties, regardless of motivation, people are more likely to reply on peripheral cues. In the cases where collaboration is not required, people are less likely to deliberately assess the others' trustworthiness. The low cognition likelihood (low ability and low motivation) leads to one's reliance on the peripheral route. When the task requires highly interdependent collaboration, people may be more motivated to deliberately evaluate the others' trustworthiness. However, due to limited interaction history and time constraints, they do not have the ability to cognitively access needed information. Thus, the low cognition likelihood (low ability and high motivation) leads individuals to rely on available peripheral cues.

Proposition 1a: Individuals form trust through the peripheral route when the low cognition likelihood (low motivation-low ability or high motivation- low ability) is a result of limited prior interaction with the other parties.

According to this proposition, virtual team members are more likely to form trust through the peripheral route. Due to reasons such as limited personal knowledge, time constraints, or the lack of traditional social cues and controls in a computer mediated communication environment, virtual team members often are not able to engage deliberate cognitive information processing and have to rely on peripheral cues available in the context.

Based on a review of theories and studies of trust in organizations, Kramer [27] summarized six antecedent conditions of trust that are posited to influence an individual's formation of trust: dispositional trust, history-based trust, third party as conduits of trust, category-based trust, role-based trust, and rule-based trust. These antecedent conditions of trust, except for the history-based condition, could be considered as the peripheral cues that serve for the formation of initial trust in the situations where personal knowledge of the interacting parties is not available or limited. These peripheral cues are represented in Figure 1.

Dispositional trust refers to individual differences in the general predisposition to trust other people $[19,35]$. Dispositional trust will influence trust before information about the others becomes available [35]. Third parties can play a crucial role in the development and diffusion of trust by acting as important "go-betweens" in new relationships, thus enabling individuals to "roll over" their expectations from well-established relationships to others in which adequate knowledge or history is not yet available [6]. Membership in a salient social or organizational category (e.g., gender, races) provides a basis for presumptive trust $[5,37,38]$. Role-based trust is another form of depersonalized trust where individuals adopt a presumption based on their knowledge of roles (e.g., doctors), in the absence of knowledge about an individual [1]. Clear role definition and role-based interaction should contribute to rapid trust development in teams where personal knowledge is limited [38]. Rulebased factors such as the situational normality and organizational structural assurance should promote initial trust [37]. Explicit and tacit understandings regarding transaction norms, interactional routines, and exchange practices provide another basis for inferring others' behavior in the absence of personal knowledge [16].

Proposition 1b: Trust formed through the peripheral route is based on an individual's disposition to trust, and their assessment of third party information, social or organizational categories, roles, and rules.

In virtual teams where tasks are complex and require high levels of collaboration, members need to presume trust in order for the teams to function quickly [38]. Thus these antecedents to presumptive trust should have 
stronger influence on trust in virtual teams. It has been observed in virtual teams that clear communication rules and role definitions are associated with high levels of trust [24], which indicates that virtual team members rely on these peripheral cues when they form their trust attitudes.

\subsection{Central route: Cognition-based trust}

The dual process theories also posit that attitude change may involve the central route of information processing where relevant information is deliberately considered $[9,42]$. The central route is activated by the individual's high motivation and ability to process relevant information. Through interactions and accumulated personal knowledge, individuals gradually gain the ability to form trust through the central route in which personal attributes are deliberately assessed. When individuals possess the ability and the motivation to assess relevant information, they use the central route to from trust. In other words, the high cognition likelihood induces individuals to form their trust toward others through deliberate cognitive assessment.

Proposition 2a: Individuals form trust through the central route when the cognition likelihood is high (high motivation-high ability).

The central route to trust (see Figure 1) is consistent with the traditional developmental view of trust. According to the traditional developmental view, trust arises from one's cognitive assessment of the attributes associated with the trustees [35], and thickens or thins as a function of their cumulative interactions [27]. This cognition-based trust or history-based trust is posited as a function of an individual's perceptions of the interacting parties' trustworthiness determined by their ability, integrity, and benevolence [35]. Ability refers to the group of skills that enable an individual to be perceived as competent within some specific domain. Integrity is the adherence to a set of principles that the trustor finds acceptable. Benevolence is the extent to which an individual is believed to feel interpersonal cares and concerns, and the willingness to do good to the trustor, aside from an egocentric profit motive. The interaction histories give individuals useful information in assessing others, and this information, in turn, provides a basis for drawing inferences regarding their trustworthiness and for making predictions about their future behavior.

Proposition 2b: Trust formed through the central route is based on individual's cognitive assessment of the other parties' ability, integrity, and benevolence.

Although it is more likely for virtual team members to form trust through the peripheral route, in the cases where they have the opportunities to accumulate personal knowledge of their teammates, they may be able to form trust through the central route where the attributes of their teammates are deliberately assessed. Jarvenpaa and Leidner [24] observed that to maintain high levels of trust in virtual teams, team members have to act on initial trust through certain communication behaviors that emphasize related personal attributes; otherwise, trust diminishes quickly. For instance, predictable communication patterns, indicating task integrity, substantial and timely responses, indicating personal task capability, and enthusiastic social communication, expressing personal benevolence, are found to be related to high level of trust in virtual teams [24]. This indicates that continuous interaction enables virtual team members to gain personal knowledge of others, reassess other members' attributes, and adjust their trust attitude through the central route.

Trust is often considered a continuum, rather than a binary trust/not trust distinction. The three trust antecedents themselves vary along a continuum and may be affected by the situation [35]. In some situations, some antecedents may be more important than others. Thus trust is formed not only using the perceived amount of the interacting parties' ability, integrity, and benevolence, but also based on the perceived importance of each of these antecedents to the situation. That is, when an individual forms trust toward other members in a team, he or she considers both the amount of these antecedents and their importance.

In a virtual team where the task often needs to be completed in a relatively short period of time, members may focus more on the task goals than on social/relational development [23 38]. Therefore, when forming trust in virtual teams, individuals may place more weight on perceived ability and integrity than on perceived benevolence. The relative importance of each antecedent may also depend upon the confidence that individuals have in their knowledge of that antecedent. Because it may take longer to develop accurate assessments of benevolence, the importance attached to benevolence may be low initially, but increase over time [see 35]. In sum, the central route to trust involves deliberate cognitive assessment of not only the amount of perceived ability, integrity, and benevolence possessed by others, but also the relative importance of each trust antecedent.

Proposition 2c: Trust formed through the central route is a function of the perceived values and the relative importance of the trust antecedents in the specific situation.

The accumulated personal knowledge through direct interactions provides a basis for the cognition-based trust $[32,35]$. This accumulated information about the others creates the foundation for the transition of trust from one stage to the other [32]. The notion of accumulating personal knowledge based on outcomes of trusting behaviors could be explain by studies about trust and monitoring behaviors [28]. These studies suggest that 
low trust is associated with the amount of monitoring of work progress. In other words, through monitoring others' behaviors, an individual will be able to accumulate personal knowledge and form more accurate perceptions of others' trustworthiness. Therefore, the outcomes of one's trusting behaviors will influence trust indirectly through his or her accumulated personal knowledge of the interacting parties.

Proposition 3a: Outcomes of an individual's trusting behavior will increase his or her personal knowledge of the other party.

Two psychological facets of trust judgment are involved in the central route [27]. First, the trustor's judgment about the trustee is anchored, in part, on prior expectations about others' behavior. Second, those expectations change in response to the extent to which subsequent experience either validate or discredit those expectations. Expectations tend to change in the direction of experience and to a degree proportional to the difference between this experience and the initial expectations applied to it [3]. The accumulated knowledge becomes a basis for initially calibrating and then updating trust-related expectations [27, 32, 35].

It has been suggested that individuals often use the "anchoring and adjustment" as an important decisionmaking heuristic [45]. In the absence of specific knowledge, individuals rely on general information that serves as an "anchor" (i.e., the peripheral route of information processing). When additional information becomes available following direct experience, individual tends to adjust their prior judgments to reflect the new information but still rely on the initial anchors (i.e., the central route of information processing). In other words, this process involves the adjustment of the anchored prior perceptions or expectations [35].

Proposition 3b: Trust formation using the central route is an "anchoring and adjustment" process involving the adjustment of the anchored values of each antecedent and the adjustment of the importance each antecedent.

\subsection{Habitual route: Habit-enacted trust}

As a relationship matures, a habitual pattern of trust may be rewarded with outcomes indicating that the trust is justified. The accumulated personal knowledge based on prior successful trust transactions contribute to a habitual trust attitude. Trust becomes a habit as it is reinforced. In addition, the interacting parties may grow emotional bonds [32, 36], and even begin to identify strongly with other's need, preferences, and priorities, and come to see them as their own [32]. This identification-based trust, based on extensive personal knowledge, contributes to a trust attitude involves affect and emotion.
Proposition 4a: The accumulation of extensive personal knowledge enables a habitual pattern of trust and may generate an emotional bond and personal identification between the parties.

A habitual pattern of trust is automatic and unconscious. Individual simply enact their previous trusting attitude with little conscious cognitive effort [46]. The emotional bonds and personal identification established through the investment of a trusting relationship further contribute to affect-based trust: trust involves little rational cognitive assessment. Under these circumstances, one's motivation to cognitively assess information is significantly reduced, even if he or she has the ability to do so. In other words, the low cognition likelihood (low motivation and high ability) leads to the use of the habitual route where neither peripheral cues nor relevant personal information is consciously used to form one's trust attitude (see Figure 1).

Proposition 4b: Individuals form trust through the habitual route when the low cognition likelihood (high ability-low motivation) is a result of a habitual pattern of trust and/or personal identification toward the other party.

Trust formed through the habitual route is based either on habitual patterns or on personal identification. It requires an existing mature trusting relationship. Given the often short life span of virtual teams, it is less likely for virtual team members to form trust through the habitual route. However, since trust formed through the habitual route is often considered stronger and more resilient to violations [32], factors that contribute to habitual trusting behaviors and/or enhancing personal identification may help managers and ICT designers support trust formation and maintenance in virtual teams.

\subsection{Situational factors and risk assessment}

Perceived risk, an assessment of the likelihood of significant and/or disappointing outcomes [44], has been identified as an essential element of trust [35]. It has been proposed to be the key factor that differentiates one's trust and trust behaviors - the difference between the willingness to assume risk and actually assuming risk [35]. Trust, as a willingness to be vulnerable to the interacting parties, will increase the likelihood of an individual's trusting behavior, but whether or not a specific risk will be taken is also influenced by the perceptions of the risk inherent in the behavior. Based on this notion, factors that influence one's trusting behaviors include one's trust toward the interacting parties and factors outside the relationship that make the decision significant and uncertain [35]. Perceived risk is therefore situational in which the possible gains and the potential losses embedded in the interaction context are considered [12]. A number of contextual factors such as task 
interdependency, problem domain familiarity, and organizational control systems have been identified to influence an individual's risk perception [43, 44].

An individual's perceived risk of the interaction context interacts with the relationship between his or her trust and trusting behavior [35]. Specifically, the level of trust is compared to the level of perceived risk. If the level of risk is perceived to be higher than the level of trust, the individual is less likely to engage in trusting behavior. On the other hand, if the level of risk perceived is lower than the level of trust, the individual is more likely to engage in trusting behavior.

Proposition 5a: The perceived risk of the situation will moderate the relationship between trust and trust behavior.

Perceived risk may also influence one's selection of routes to trust. The level of risk perceived in the interacting context may influence an individual's motivation to deliberately process information. The higher the perceived risk, the more likely it is for an individual to be motivated to deliberate on relevant information. High motivation triggered by high perceived risk will increase the cognition likelihood, which in turn, leads to the central route to trust. The ultimate route used depends on one's ability to deliberate on information, i.e., the level of accumulated personal knowledge.

Proposition 5b: The higher the perceived risk, the more likely the central route will be used.

\subsection{Communication environment and trust}

In virtual teams where work is often conducted through ICTs, the influence of communication environment becomes salient. Although there are several ways to classify communication environments, one way is to differentiate traditional face-to-face communication with computer mediated communication.

Developmental differences between face-to-face teams and computer mediated teams have been welldocumented [10, 47]. Findings of theses studies suggested that although computer-mediated teams can achieve the same level of relationship development, it often takes them longer than face-to-face teams. In traditional face-to-face communication environment where richer social cues are available and outcomes of one's trust behaviors can be assessed in a timely manner, individuals are able to accumulated personal knowledge of the interacting parties at a faster rate. Whereas in a mediated communication environment, fewer social cues coupled with the possible asynchronous interaction limits individuals' ability to quickly accumulate personal knowledge based on outcomes. In short-term collaborations, personal relationships may never develop [47]. Therefore, we propose that compared to traditional face-to-face interactions, the time required to accumulate sufficient knowledge for valid personal assessment will be longer in computer mediated communication environment.

Proposition 6a: Extensive use of computer mediated communication will slow the accumulation of personal knowledge.

For collaboration actions to be successful, one should either possess the ability to closely monitor or trust the involved parties [41]. The ability to control the others is, thus, inextricably interlinked with perceived risk [13] the lower the perceived control, the greater the perceived risk. In face-to-face communication, individuals can exercise control via social control and coordination such as direct supervision, geographically collocation, similar backgrounds, and shared experiences [23]. However, in mediated communication, these social control and collaboration mechanisms may no longer be available [23]. Role overload, role ambiguity, absenteeism, and social loafing often observed in short-term computer mediated collaboration [23, 40] may further increase one's perception of risk. Experience with various communication media may also interfere with one's perception of risk. Computer anxiety [22] due to the need to simultaneously deal with the communication media [11] may cause one to perceive higher risk in the interaction context. We propose that the communication environment will influence one's perception of risk. Specifically, one will perceive the risk to be higher in a computer mediated communication environment.

Proposition 6b: Extensive use of computer mediated communication will increase perceived risk.

\section{Implications for Research and Practice}

\subsection{Trust over time}

Relationship development encompasses different stages or forms over time [32], so trust is not static. However, the existing models of trust, regardless whether they are originated from the traditional developmental view $[35,36]$ or from the models of swift trust/initial trust [37, 38], often model trust from a static viewpoint. Focusing on a static point of time, researchers may find trust manifested itself in different forms. For instance, trust is often categorized as presumptive [37, 38], deterrence- or calculus-based, knowledge- or cognitionbased, and identification- or affect-based [35, 36].

The integrated model of trust proposed in this paper embraces the dynamic nature of trust formation and development by examining the three possible routes to trust. The three routes to trust represent the gradual shift of bases for trust formation over time as one gains personal experience and knowledge of the involved parties. While prior models describing different forms of trust emphasize trust observed at different points in time, 
our proposed model integrates the different forms of trust and focuses on the dynamic shifts of trust over time by using a fundamental theoretical framework. Important questions remain, such as how trust can be effectively managed, what levels of personal knowledge will shift the routes, and how trust formed through different routes influences team performance. Future research focusing on the dynamic nature of trust and the shift of routes over time will be able to provide us further insights of how trust could be effectively managed over time.

The managerial strategies for managing trust also need to incorporate this dynamic aspect of trust. To effectively manage trust, one needs to identify the stages of the relationship and emphasize their bases of trust formation. At the initial stages of a relationship or in short life span collaboration of virtual teams, trust is mainly determined by peripheral and situational factors. To enhance presumptive trust, managerial emphasis should be placed on providing individuals strong and clear peripheral cues such as well-defined roles, rules, increased reputational capital [38], and illusion of control [29]. At the middle stages of a relationship, the cognitive dimension of trust plays a critical role in determining one's level of trust. Thus, the interacting parties' trustworthiness in terms of ability, integrity, and benevolence should be emphasized. At the later stages of a work relationship, the emotional dimension of trust is critical for maintaining a trusting relationship. In this case, managers should strengthen the emotional bonds to support habit-enacted trust.

\subsection{Trust fragility and resilience}

The different forms of trust vary in fragility and resilience $[32,38]$. Trust associated with close personal relationships from the habitual route is a "thick" form of trust that is relatively resilient and durable $[32,36]$. This type of trust, once developed, is not easily disrupted, but once shattered, it is not easily restored $[32,38]$.

In contrast, trust formed via the peripheral route has been characterized as fragile or "thin" because it is conferred cautiously and withdrawn readily $[32,37,38]$. Trust formed this way is primarily based on the peripheral cues through the use of category-driven information processing [38]. Although the reliance on past personal experience in similar situations or on general social norms and perceptions allows rapid development of trust, when applied to a specific interaction context, it is often prone to error. Lacking the personal knowledge as the basis for forming proper expectations, trust is superficial. Even minor violations could easily to lead to distrust [32]. Therefore, trust formed through the peripheral route is often considered fragile or "thin". However, trust formed through the peripheral route is easier to be repaired once related peripheral cues are clarified or renegotiated.
When personal knowledge of the other parties accumulates, trust is formed through the central route where deliberate cognitive information processing is involved. Trust through central route is posited to be an anchored and adjustment process of the values and importance of trust antecedents. Thus, even though a violation of trust may reduce one's perceived values of trust antecedents, its influence of trust may be less significant given the different importance each antecedent has on trust. Trust formed through the central route is less fragile and more resilient to violations, but is more difficult to repair than trust formed via the peripheral route because it involves deliberate personal judgments. Violation of trust may represent a threat to an individual's confidence in his or her personal knowledge and in the predictability of the others [32].

Trust formed through the habitual route is triggered by a habitual pattern that may encompass strong emotional bonds and personal identification. This habitual pattern and the emotional bonds reduce one's desire to form new trust attitudes. In this case, trust is violated when the actions are perceived to be against the established common values. With the strong emotional bond and personal identification, for an individual to accept invalidating information, he or she must be willing to acknowledge that his or her habitual pattern of trust was ill-founded - these dissonant cognitions are identity challenging and may be rejected as self-preservation [32]. Though trust formed through this route is generally robust, once destroyed, its repair is extremely difficult [32]. A serious violation damage one's identification and commitment to the other, and leads one to question his or her knowledge of the other [32]. Therefore, once the base of trust is destroyed, it is difficult to restore.

Strategies for managing trust need to consider the fragility and resilience to violation of trust at different developmental stages. In order to promote the formation of more robust trust, managerial efforts should be made to shift trust formation from the peripheral route to the central or habitual route, in addition to maintain trust in its present form. To maintain and strengthen trust in its current form, managers should pay attention to the factors that determine the specific form of trust, and carefully mange the levels of risks perceived. For instance, mechanisms such as the reputation of board-certifications and professional degrees can be used to strengthen presumptive trust by providing individuals a cognitive base for conferring trust and to reduce perceptions of uncertainty and complexity [38]. To shift trust from a more fragile form to a more robust form, managers should provide opportunities for accumulating personal knowledge among the parties [38]. Strategies to manage trust fragility, should reduce the level of perceived risk by providing additional insurances, and at the same time, 
shift trust to a more robust form by allowing personal knowledge accumulation through positive experience.

\subsection{Facilitating trust in electronically mediated communication environments}

Communication environments can have indirect influences on trust and trust behaviors. Individuals may perceive higher risk in a computer mediated communication environment and therefore, be more motivated to form trust through the central route. However, the need to deliberate on personal information is inhibited by the slower accumulation of personal knowledge in such environments. Therefore, trust management represents a special challenge for individuals who communicate and collaborate mainly through ICTs. Managerial strategies for managing trust in computer mediated communication environment will have to, on one hand, reduce the levels of perceived risk, and on the other, provide opportunities for individuals to build relationships and to accumulate personal knowledge.

Research on how exactly communication environments may influence the development and maintenance of trust is still in its infancy. Empirical studies are required to verify our propositions regarding the influence of communication environments on trust formation and maintenance. Future studies may examine how various ICT characteristics (e.g., communication, information processing, and process support mechanisms), individually or combined, may influence individuals' perceptions of the interaction experience (e.g., perceived risk). As individuals shift routes to trust formation, what behaviors and processes involving the use of an ICT may promote or inhibit the development and maintenance of trust in a team?

For managers, effective strategies for managing computer mediated communication and interaction should consider the following issues. First, attention should be paid to the peripheral cues when individuals have limited prior interaction and communicate mainly through the use of ICTs (e.g., virtual team). In this case where the shift from the peripheral route to the central and habitual routes takes longer to occur, the influence of peripheral cues on trust becomes more salient. For example, categorical stereotypes [48] are more likely to be stronger and persist longer. Ambiguous roles and rules in virtual teams may have a greater negative impact on trust development [38].

Second, with computer mediated communication and collaboration, individuals have fewer opportunities to engage in more traditional, face-to-face trust building activities. Thus, team support mechanisms such as teambuilding exercises may be utilized to reduce negative biases and stereotypical attributions by providing chances for individuals to build relationships and accumulate personal knowledge of each other. Such exercises may speed up the transition process from the peripheral route to the central and habitual routes.

Third, well established rules and patterns of using various communication media could increase the level of control perceived by individuals and in turn, strengthen trust [24]. Actions such as proactive and task output orientations, explicit time and process management, and frequent and predicative communication will facilitate the development and maintenance of trust in mediated communication environments $[23,24]$.

\section{References}

1. Barber, B. The Logic and Limits of Trust, Rutgers University Press, New Brunswick, NJ, 1983.

2. Bews, N.F., and Rossouw, G.J. "A Role for Business Ethics in Facilitating Trustworthiness," Journal of Business Ethics, (39:4), 2002, pp. 377-390.

3. Boyle, R., and Bonacich, P. "The Development of Trust and Mistrust in Mixed-Motive Games," Sociometry, (33), 1970, pp. 123-139.

4. Bradach, J.L., and Eccles, R.G. "Price, Authority, and Trust - From Ideal types to Plural Forms," Annual Review of Sociology, (15), 1989, pp. 97-118.

5. Brewer, M.B. "Ethnocentrism and Its Role in Interpersonal Trust," in Scientific Inquiry and the Social Sciences, Brewer, M. B. and B. E. Collins (eds.), Jossey-Bass, San Francisco, 1981.

6. Burt, R.S., and Knez, M. "Kind of Third-Party Effects on Trust," Rationality and Society, (7), 1995, pp. 225-292.

7. Cacioppo, J.T., Petty, R.E., Kao, C.F., and Rodriguez, R., "Central and Peripheral Routes to Persuasion: An Individual Difference Approach," Journal of Personality and Social Psychology, 51:5, 1986, pp. 1032-1043.

8. Cascio, W. "Managing a Virtual Workplace," Academy of Management Executive, (14:3), 2000, pp. 81-90.

9. Chaiken, S. "Heuristic versus systematic information processing and the use of source versus message cues in persuasion," Journal of Personality and Social Psychology, (39:5), 1980, pp.752-766.

10. Chidambaram, L. "Relational Development in ComputerSupported Groups," MIS Quarterly, (20:2), 1996, 143-165.

11. Chua, S.L., Chen, D.T., and Wong, A.F.L. "Computer Anxiety and Its Correlates: A Meta-Analysis," Computers in Human Behavior, (15:5), 1999, pp. 609-623.

12. Coleman, J.S. Foundations of Social Theory, Harvard University Press, Cambridge, MA, 1990.

13. Das, T.K., and Teng, B. 2001. "Trust, Control, and Risk in Strategic Alliances: An Integrated Framework," Organization Studies, (22:2), 2001, pp.251-283.

14. Dirks, K.T., and Ferrin, D.L. "Trust in Leadership: MetaAnalytic Findings and Implications for Research and Practice," Journal of Applied Psychology, (87:4), 2002, pp.611-628.

15. Duarte, D.L., and Snyder, N.T. Mastering Virtual Teams, Jossey-Bass, San Francisco, 1999.

16. Fine, G.A., and Holyfield, L. "Secrecy, Trust, and Dangerous Leisure: Generating Group Cohesion in 
Voluntary Organizations," Social Psychology Quarterly, (59), 1996, pp.22-38.

17. Fiske, S.T., and Taylor, S.F. Social Cognition ( $2^{\text {nd }}$ ed.), McGraw-Hill, New York, 1991.

18. Gudykunst, W.B., and Ting-Toomey, S. Culture and Interpersonal Communication, Thousand Oaks, CA: Sage Publications, 1988.

19. Gurtman, M.B. "Trust, Distrust, and Interpersonal Problems: A Circumplex Analysis," Journal of Personal Sociology Psychology, (62), 1992, pp.989-1002.

20. Handy, C. "Trust and Virtual Organization," Harvard Business Review, (73:3), 1995, pp.40-50.

21. Hardin, R. "The Street-Level Epistemology of Trust," Politics \& Society, (21:4), 1993, pp.505-529.

22. Igbaria, M., and Parasuraman, S. "A Path Analytic Study of Individual Characteristics, Computer Anxiety, and Attitudes toward Microcomputers," Journal of Management, (15:3), 1989, pp.373-388.

23. Jarvenpaa, S.L., Knoll, K., and Leidner, D.E. "Is Anybody Out There? The Implications of Trust in Global Virtual Teams," Journal of Management Information Systems, (14:4), 1998, pp.29-64.

24. Jarvenpaa, S.L., and Leidner, D.E. "Communication and Trust in Global Virtual Teams," Organization Science, (10), 1999 , pp.791-815.

25. Klimoski, R.J., and Karol, B.L. "The Impact of Trust on Creative Problem Solving Groups," Journal of Applied Psychology, (61), 1976, pp.630-633.

26. Kramer, R.M. "The Sinister Attribution Error: Paranoid Cognition and Collective Distrust in Organizations," Motivation and Emotion, (18), 1994, pp.199-230.

27. Kramer, R.M. "Trust and Distrust in Organizations: Emerging Perspectives, Enduring Questions," Annual Review Psychology, (50), 1999, pp.569-598.

28. Kruglanski, A.W. "Attributing Trustworthiness in Supervisor-Worker Relations," Journal of Experimental Psychology, (6), 1970, pp.214-232.

29. Langer, E.J. "The illusion of control," Journal of Personality and Social Psychology, (32), 1975, pp. 311-328.

30. Laver, M. The Politics of Private Desires: The Guide to the Politics of Rational Choice, Penguin, New York, 1981.

31. Lewicki, R.J., and Bunker, B.B. "Trust in Relationships: A Model of Trust Development and Decline," in Conflicts, Cooperation, and Justice, Bunker, B.B., and J.Z. Rubin (eds.), Jossey-Bass, San Francisco, 1995.

32. Lewicki, R.J., and Bunker, B.B. "Developing and Maintaining Trust in Work Relationships," in Trust in Organizations: Frontiers of Theory and Research, R.M. Kramer, R.M., and T.R. Tyler (eds.), Sage Publications, Thousand Oaks, CA, 1996, pp.114-165.

33. Lewicki, R.J., McAllister, D.J., and Bies, R.J. "Trust and Distrust: New Relationships and Realities," Academy of Management Review, (23:3), 1998, pp.438-458.

34. Lewis, J.D., and Weigert, A. "Trust as a Social Reality," Social Forces, (63), 1985, pp.967-985.

35. Mayer, R.C., Davis, J.H., and Schoorman, F.D. "An Integrative Model of Organizational Trust," Academy of Management Review, (20), 1995, pp.709-734.

36. McAllister, D.J. "Affect- and Cognition-Based Trust as Foundations for Interpersonal Cooperation in
Organizations," Academy of Management Journal, (38), 1995, pp.24-59.

37. McKnight, D.H., Cummings, L.L., and Chervany, N.L. "Initial Trust Formation in New Organizational Relationships," Academy of Management Review, (23), 1998, pp.473-490.

38. Meyerson, D., Weick, K.E., and Kramer, R.M. "Swift Trust and Temporary Groups," in Trust in Organizations: Frontiers of Theory and Research, Kramer, R.M., and T.R. Tyler (eds.), Sage Publications, Thousand Oaks, CA, 1996, pp.166-195.

39. Miller, G., and Steinberg, M. Between People, Science Research Associates, Chicago, 1975.

40. O'Hara-Devereaux, M., and Johansen, B. Global Work: Bridge Distance, Culture, and Time, Jossey-Bass, San Francisco, 1994.

41. Ouchi, W.G. "A Conceptual Framework for the Design of Organizational Control Mechanisms," Management Science, (25:9), 1979, pp.833-48.

42. Petty, R.E. \& Cacioppo, J.T. Communication and Persuasion: Central and Peripheral Routes to Attitude Change, Springer-Verlag, New York, 1986.

43. Sheppard, B.H., and Sherman, D.M. "The Grammars of Trust: A Model and General Implication," Academy of Management Review, (23:3), 1998, pp.422-437.

44. Sitkin, S.B., and Pablo, A.L. "Reconceptualizing the Determinants of Risk Behavior," Academy of Management Review, (17:1), 1992, pp.9-38.

45. Strickland, L.H. "Surveillance and Trust," Journal of Personality, (26), 1958, pp.200-215.

46. Triandis, H.C. Attitude and Attitude Change, John Wiley and Sons, Inc., New York, NY. 1971.

47. Walther, J.B. "Relational Aspects of Computer-Mediated Communication: Experimental Observations over Time," Organization Science, (6:2), 1995, pp.186-203.

48. Williams, M. "In Whom We Trust: Group Membership as an Affective Context for Trust Development," Academy of Management Review, (26:3), 2001, pp.377-396. 